\title{
Characterization of biochars produced from oil palm and rice husks and their adsorption capacities for heavy metals
}

\begin{abstract}
The objectives of this study were to determine the selected physicochemical properties of two biochars, one commercially produced from rice husks and the other from oil palm empty fruit bunches, and to evaluate their adsorption capacities for $\mathrm{Zn}, \mathrm{Cu}$, and $\mathrm{Pb}$ using a batch equilibrium method. The results showed that there was no significant difference between the carbon content of biochars formed from empty fruit bunches (EFBB) and rice husks (RHB). However, the EFBB did present higher quantities of $\mathrm{O}, \mathrm{H}, \mathrm{S}, \mathrm{N}$, and $\mathrm{K}$, compared to the RHB. Although the EFBB had a much lower surface area than the RHB, the former adsorbed much more $\mathrm{Zn}, \mathrm{Cu}$, and $\mathrm{Pb}$ than the RHB. The higher adsorption capacity of the EFBB over the RHB was a result of the EFBB having higher amounts of oxygen-containing functional groups, a higher molar ratio of $\mathrm{O} / \mathrm{C}$, and a higher polarity index $[(\mathrm{O}+\mathrm{N}) / \mathrm{C}]$. This suggests that the biochar's chemical properties were more important than its surface area in the adsorption of $\mathrm{Zn}, \mathrm{Cu}$, and $\mathrm{Pb}$.
\end{abstract}

Keyword: Adsorption; Functional groups; Heavy metals; Surface area 